\title{
Increasing our knowledge of germline variants
}

\author{
Noriomi Matsumura ${ }^{1}$
}

Published online: 20 January 2022

(c) The Author(s) under exclusive licence to The Japan Society of Clinical Oncology 2022

Mikoshiba et al. report a carotid body tumor with cervical lymph node metastasis in a 43-year-old Japanese man due to a germline $S D H B$ variant; c. $136 \mathrm{C}>\mathrm{T}$ (p. Arg46*) [1]. The patient achieved long-term disease-free survival after surgery. This report suggests that genetic testing for $S D H B$ may provide important information for treatment and followup strategies for carotid body tumors.

Saita et al. report a triple-negative breast cancer in a 39-year-old Japanese woman with a germline BRCAl variant; c.5332G > A (p.Asp1778Asn), which was determined to be VUS [2]. Because this variant was determined to be VUS, she did not undergo risk-reducing surgery. She was subsequently diagnosed with stage III high-grade serous ovarian cancer. And the BRCAl variant; c. $5332 \mathrm{G}>\mathrm{A}$ (p.Asp1778Asn) had been changed to "likely pathogenic". This case report reinforces the evidence for pathogenicity of this variant. And this report also shows the importance of periodically checking whether the VUS decision subsequently changes to (likely) pathogenic.
The significance of individual germline variants is revealed by the accumulation of individual case reports. Therefore, journals that publish case reports, such as our journal, play an important role in clarifying the significance of germline variants.

\section{References}

1. Mikoshiba T, Yoshihama K, Ito F et al (2021) Carotid body tumor with neck metastasis due to germline $S D H B$ variant: a case report and literature review. Int Canc Conf J. https://doi.org/10.1007/ s13691-021-00522-x

2. Saita C, Aruga T, Adachi M et al (2021) Germline variant BRCA1 c.5332G $>$ A has clinical features of hereditary breast and ovarian cancer syndrome. Int Cancer Conf J. https://doi.org/10. 1007/s13691-021-00512-z

Publisher's Note Springer Nature remains neutral with regard to jurisdictional claims in published maps and institutional affiliations.
This issue contains two articles on germline variants.

Noriomi Matsumura

noriomi@med.kindai.ac.jp

1 Faculty of Medicine, Kindai University, Osaka-Sayama, Japan 